\title{
Isolation of Cancer Stem Cells and Astrocytes from Human Glioblastoma: Morphological Characterization of Two Cells Types
}

\author{
Mansoureh Hashemi ${ }^{*}$ (D) \\ ${ }^{1}$ Functional Neurosurgery Research Center, Shahid Beheshti University of Medical Sciences, Tehran, Iran
}

\begin{abstract}
Background: Glioblastoma multiforme is the most aggressive astrocytoma in adults. Glioblastoma is a heterogenous tumor formed from various cells including astrocyte and cancer stem cells. Here, we explain the isolation, culture, morphology and specific markers of human glioblastoma astrocyte and stem cells. Methods: We isolated astrocyte and cancer stem cells from human glioblastoma tissue. The obtained glioblastoma tissues were digested and cultured in DMEM12, B27 supplemented with basic fibroblast growth factor and epidermal growth factor. The morphology and specific markers were assessed in astrocyte and cancer stem cell of human glioblastoma through immunocytochemistry.

Results: Results indicated that there were two morphology types in cell culture including epithelioid morphology and fibroblastic morphology. The astrocyte confirmed via expression of the Glial fibrillary acidic protein (GFAP) protein. Cancer stem cells were round and floating in the culture medium. Immunocytochemical staining indicated that nestin and SRY-box 2 (SOX2) antigens were positively expressed in primary neurospheres.

Conclusion: The expression of glial and stem cell markers shows that both cells are in the human glioblastoma.

Keywords: Glioblastoma multiforme; Astrocyte; Cancer stem cell; Morphology.
\end{abstract}

\author{
*Correspondence to \\ Mansoureh Hashemi, \\ Shohada Tajrish Hospital, \\ Functional Neurosurgery \\ Research Center, Sharadari \\ St., Tajrish Square, Tehran \\ 1989934148, Iran \\ Fax: +98 2122701022; \\ Email: mansoureh.hashemi@ \\ sbmu.ac.ir
}

Published online December 30,2020

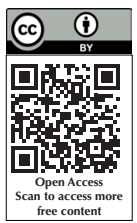

Citation: Hashemi M. Isolation of cancer stem cells and astrocytes from human glioblastoma: morphological characterization of two cells types. Clin Neurosci J. 2021;8(1):22-25. doi:10.34172/icnj.2021.05.

\section{Introduction}

astrocytomas are the most common group of primary brain tumors in the brain comprising $30-40 \%$ of all brain tumors. ${ }^{1}$ Glioblastoma multiforme constitute $52 \%$ of primary brain tumors. The most prevalent age of glioblastoma is about 50-55 years and men are more prone to this brain tumor. Prognosis of glioblastoma is poor and the survival rate is 14.6 months after diagnosis. ${ }^{2}$ Important risk factors for glioblastoma are high dose radiation, hereditary syndromes, and age increase. ${ }^{3}$

Glioblastoma is formed of a heterogenous tissue containing differentiated astrocytes and cancer stem cells. ${ }^{4}$ The two properties of cancer stem cells are unlimited selfrenewal and multipotency. There are two stem cell niches in the adult mammalian brain including the dentate gyrus ${ }^{5}$ and the subventricular zone. ${ }^{6}$ Neural precursor cells seem to play an important role in the initiation and progression of different neurological diseases including Alzheimer's disease, Parkinson's disease, stroke, epilepsy, and schizophrenia. ${ }^{7}$ Also, theories were reported that neural precursor cells can be the origin of primary brain tumors. ${ }^{8}$ Specific gene alterations and diverse cellular differentiation can lead to primary brain tumors. ${ }^{5}$ However, there is strong evidence that neural precursor cells are the origin of glial tumors. ${ }^{9}$ Two models have been suggested to clarify the initiation and progression of brain tumors including the stochastic model and the hierarchical model. The stochastic model explained that the tumor is formed of various or heterogeneous cells and all the cells are able to produce tumor. On the other hand, the hierarchical model refers to malignancies that are composed of cancer stem cells or initiating cells of tumor. Furthermore, cancer stem cells have the potential to produce tumors ${ }^{10}$ and through drug resistance and genetic disorders, they can lead to therapy failure in tumors. ${ }^{11}$ In this study, we focused on two cells types forming human glioblastoma and evaluated the morphology and antigen of differentiated astrocyte and cancer stem cells.

\section{Material and Methods}

Isolation of Astrocyte From Human Glioblastoma Tissue Glioblastoma tissue was confirmed by pathological assessment. Tissue was digested with $0.05 \%$ trypsinEDTA for 10 minutes at $37^{\circ} \mathrm{C}$ in a water bath. Tissue centrifugation was performed at $1000 \mathrm{rpm}$ for 5 minutes, DMEM/F12 medium containing $1 \%(100 \quad \mathrm{U} / \mathrm{mL})$ antibiotic/antimycotic and $2 \%$ fetal bovine serum (FBS) was added to cells and then, incubated in $5 \% \mathrm{CO}_{2}$ at $37^{\circ} \mathrm{C}$

(C) 2021 The Author(s). This is an open access article distributed under the terms of the Creative Commons Attribution License (http:// creativecommons.org/licenses/by/4.0/), which permits unrestricted use, distribution, and reproduction in any medium, provided the original work is properly cited. 
for 14 days. The medium containing FBS was changed every three days in the culture.

\section{Isolation of Cancer Stem Cells From Human Glioblastoma Tissue}

The pieces of glioblastoma tissue were washed three times in calcium and magnesium free Hank's balanced salt solution (HBSS) with $1 \%$ penicillin and streptomycin. Then, the tissue was digested and incubated in trypsin for 20 minutes. Digestion was stopped by trypsin inhibitor $(80 \mu \mathrm{g} / \mathrm{mL})$ in HBSS solution. Then, centrifugation was done at $1000 \mathrm{~g}$ for 5 minutes, at room temperature. The digested tissues were triturated in DMEM/F12 with a flamed polished Pasteur pipette and filtering was performed using a $70 \mu \mathrm{m}$ strainer. The cell suspension was cultured in six well-plates with DMEM/F12 containing 20 $\mathrm{ng} / \mathrm{mL}$, epidermal growth factor (EGF), $20 \mathrm{ng} / \mathrm{mL}$, basic fibroblast growth factor (bFGF), $1 \%$ glutamax 1\% B27, $1 \%$ penicillin-streptomycin. The cells were incubated at $5 \% \mathrm{CO}_{2}, 37^{\circ} \mathrm{C}$. The medium in the supplements was changed every 2-3 days.

\section{Immunocytochemistry}

Cells were fixed in $4 \%$ paraformaldehyde in $0.2 \mathrm{M}$ phosphate-buffered saline (PBS) for 20 minutes, and then washed with PBS three times. Then, cells were permeabilized in $0.2 \%$ Triton X-100 in PBS for 5 minutes at room temperature. Then, cells were blocked in $10 \%$ albumin bovine serum for 1 hour at room temperature and incubated with primary antibodies of rabbit anti-nestin (1:250; Abcam), rabbit anti-SOX2 (1:500; Abcam), and rabbit anti-GFAP (1:300, Abcam) overnight at $4^{\circ} \mathrm{C}$. After being washed with PBS, the cells were incubated with secondary antibody of 1:200 fluorescein isothiocyanate (FITC)-conjugated goat anti-rabbit (Abcam, USA) for 2 hours at room temperature. Finally, protein expression in the cells were observed using an inverted fluorescence microscopy.

\section{Statistical Analysis}

All tests were repeated in the three independent experiments. The data were qualitative and were reported as images.

\section{Results}

\section{Astrocytes Morphology of Human Glioblastoma Multiforme}

Astrocytes were derived from human glioblastoma tissue (Figure 1A). Results indicated that there were two morphology types in cell culture. 1) Epithelioid morphology was observed to be large, abundance cytoplasm and interconnecting processes (Figure 1B). 2) Fibroblastic morphology was slender, elongated, and spindle-shaped (Figure 1C). The immunocytochemistry test indicated the expression of GFAP protein in the cells, confirming the presence of the astrocyte in the culture
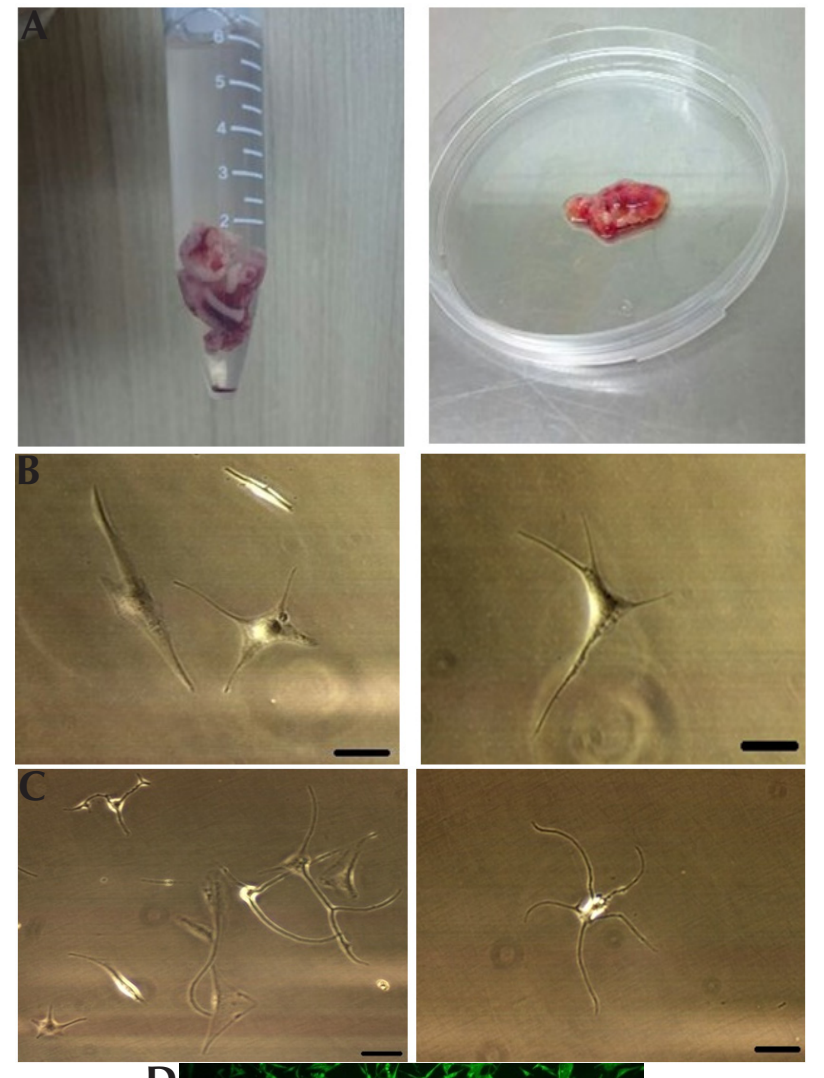

D

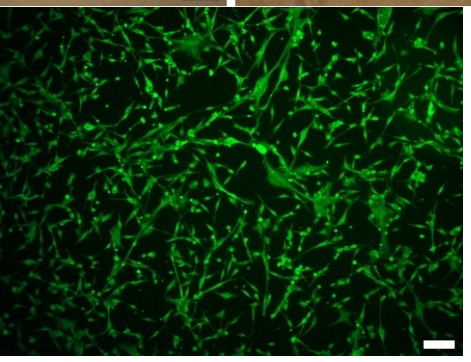

Figure 1. Morphology of the Astrocyte Types. (A) tissue of the human glioblastoma. (B) Astrocytes with epithelioid morphology, scale bar: $100 \mu \mathrm{m}$. (C) Astrocytes with fibroblastic morphology, scale bar: $100 \mu \mathrm{m}$. (D) Confirmation of cultured astrocytes through expression of GFAP protein in the cells, scale bar: $50 \mu \mathrm{m}$.

medium (Figure 1D).

\section{Isolation and Culture of Adult Human Glioblastoma Cancer Stem Cells}

Cancer stem cells were isolated and cultured from human adult glioblastoma tissue. The floating single cells started to grow, divide and form small clusters for 6-8 weeks. Neurosphere morphology was observed to be round and floating in the culture medium (Figure 2).

\section{Antigen Evaluation of Cancer Stem Cells of Human Glioblastoma}

The cancer stem cells of glioblastoma were assessed using immunochemistry test for expression of the nestin and SOX2 antigens. Immunocytochemical staining indicated that nestin and SOX2 antigens were positively expressed 

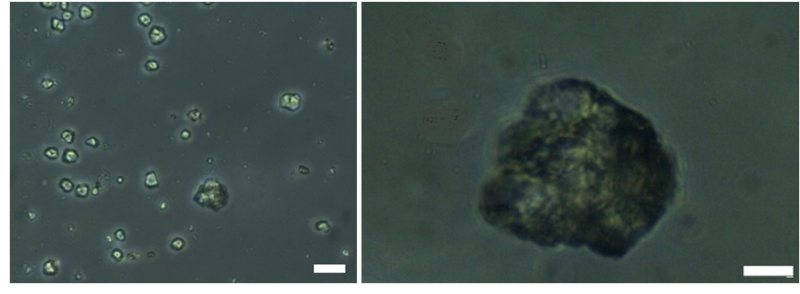

Figure 2. Morphology of Cancer Stem Cell Derived From Human Glioblastoma Tissue. Scale bar of the left image: $50 \mu \mathrm{m}$, Scale bar of the right image: $100 \mu \mathrm{m}$.
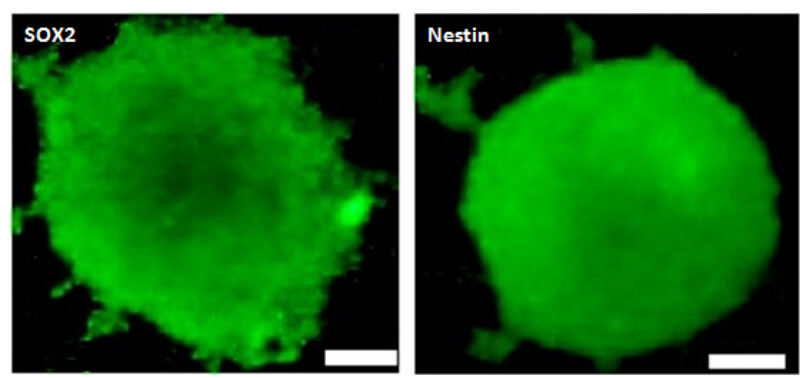

Figure 3. Expression of the Nestin and SOX2 Antigens in the Cancer Stem Cells Derived From Human Glioblastoma Tissue. Scale bar of the right image: $100 \mu \mathrm{m}$.

in primary neurospheres (Figure 3).

\section{Discussion}

In our study, we separated cancer stem cells and astrocyte from glioblastoma tissue, and found that the isolated cells have a morphology similar to cancer stem cells: sphere-like form, self-renewal, potential of differentiation. We further evaluated the other properties of cancer stem cells on our isolated cells. Nestin and SOX2 were selected to assess the property of cancer stem cells. Many studies select nestin as a marker to evaluate the features of brain cancer stem cells. ${ }^{12}$ New results also reported that nestin was overexpressed in glioblastoma stem cells. ${ }^{13}$ In our study, the isolated cells were nestin positive, indicating cancer stem cells. We cultured the cancer stem cells in the medium similar to neural stem cells and noticed this method could lead to growth of the cancer stem cells. Astrocytes are a differentiated cell in the glioblastoma. This cell is generally located in the periphery part of glioblastoma. It seems that astrocytes of glioblastoma are differentiated from glioblastoma stem cells. ${ }^{9}$ Astrocytes were GFAP positive. GFAP is a specific marker of astrocyte. ${ }^{14}$

Cancer stem cells play different roles in glioblastoma including the ability to proliferate and differentiate, tropism and migration potential to other regions, resistance to drugs and toxins, and resistance to apoptosis..$^{15}$ Studies were reported that cancer stem cells are dangerous and lead to poor diagnosis, therapy resistance and increase of morbidity and mortality in patients with glioblastoma. ${ }^{16}$ Information about cancer stem cells features could be helpful in how glioblastoma is formed and involved in tumorigenesis. Also, we can assess cellular and molecular mechanism of cancer stem cell tumorigenesis in order to find the suitable therapy approach. Unfortunately, it remains ambiguous whether cancer stem cells are derived from the transformation of normal neural stem cells or whether the differentiation of a mature brain cell is responsible. ${ }^{17}$ These theories may lead to new pathways to introduce therapeutic and pharmacological approaches for glioblastoma.

\section{Conclusion}

In this study, we successfully isolated and cultured astrocyte and cancer stem cells from glioblastoma tissue. Furthermore, we reported the features and morphology of cancer stem cells and astrocytes in the human glioblastoma tissue. However, glioblastoma is a heterogenous and complex brain tumor.

\section{Conflict of Interest Disclosures}

The authors declare that they have no conflict of interests.

\section{Acknowledgements}

The author would like to thank the Functional Neurosurgery Research Center, Shahid Beheshti University of Medical Sciences, Tehran, Iran.

\section{Funding/Support}

This study was supported by the Functional Neurosurgery Research Center, Shahid Beheshti University of Medical Sciences, Tehran, Iran.

\section{Ethical Statement}

The study was performed according to the principles of the Ethics Committee of Shahid Beheshti University of Medical Sciences with ethical code: IR.SBMU.RETECH.REC.015 for molecular and Cellular study.

\section{References}

1. Johnson DR, Guerin JB, Giannini C, Morris JM, Eckel LJ, Kaufmann TJ. 2016 updates to the WHO brain tumor classification system: what the radiologist needs to know. Radiographics. 2017;37(7):2164-80. doi: 10.1148/ rg.2017170037.

2. Stupp R, Mason WP, van den Bent MJ, Weller M, Fisher B, Taphoorn MJ, et al. Radiotherapy plus concomitant and adjuvant temozolomide for glioblastoma. N Engl J Med. 2005;352(10):987-96. doi: 10.1056/NEJMoa043330.

3. DeAngelis LM. Brain tumors. N Engl J Med. 2001;344(2):11423. doi: 10.1056/nejm200101113440207.

4. Holland EC. Gliomagenesis: genetic alterations and mouse models. Nat Rev Genet. 2001;2(2):120-9. doi: $10.1038 / 35052535$.

5. Gage FH. Mammalian neural stem cells. Science. 2000;287(5457):1433-8. doi: 10.1126/ science.287.5457.1433.

6. Lacar B, Young SZ, Platel JC, Bordey A. Imaging and recording subventricular zone progenitor cells in live tissue of postnatal mice. Front Neurosci. 2010;4:43. doi: 10.3389/ fnins.2010.00043. 
7. Jellinger KA. Adult neurogenesis: stem cells and neuronal development in the adult brain. Eur J Neurol. 2007;14(3):e13. doi: 10.1111/j.1468-1331.2007.01730.x.

8. Aboody KS, Brown A, Rainov NG, Bower KA, Liu S, Yang W, et al. Neural stem cells display extensive tropism for pathology in adult brain: evidence from intracranial gliomas. Proc Natl Acad Sci U S A. 2000;97(23):12846-51. doi: 10.1073/ pnas.97.23.12846.

9. Kato H, Takahashi A, Itoyama Y. Cell cycle protein expression in proliferating microglia and astrocytes following transient global cerebral ischemia in the rat. Brain Res Bull. 2003;60(3):215-21. doi: 10.1016/s0361-9230(03)00036-4.

10. Vescovi AL, Galli R, Reynolds BA. Brain tumour stem cells. Nat Rev Cancer. 2006;6(6):425-36. doi: 10.1038/nrc1889.

11. Zhou BB, Zhang H, Damelin M, Geles KG, Grindley JC, Dirks PB. Tumour-initiating cells: challenges and opportunities for anticancer drug discovery. Nat Rev Drug Discov. 2009;8(10):806-23. doi: 10.1038/nrd2137.

12. Hoffman RM. The potential of nestin-expressing hair follicle stem cells in regenerative medicine. Expert Opin Biol Ther. 2007;7(3):289-91. doi: 10.1517/14712598.7.3.289.

13. Hwang HS, Cho NH, Maeng YS, Kang MH, Park YW, Kim $\mathrm{YH}$. Differential expression of nestin in normal and pre- eclamptic human placentas. Acta Obstet Gynecol Scand. 2007;86(8):909-14. doi: 10.1080/00016340701417018.

14. Ghods AJ, Irvin D, Liu G, Yuan X, Abdulkadir IR, Tunici $\mathrm{P}$, et al. Spheres isolated from $9 \mathrm{~L}$ gliosarcoma rat cell line possess chemoresistant and aggressive cancer stemlike cells. Stem Cells. 2007;25(7):1645-53. doi: 10.1634/ stemcells.2006-0624.

15. Galli R, Binda E, Orfanelli U, Cipelletti B, Gritti A, De Vitis $\mathrm{S}$, et al. Isolation and characterization of tumorigenic, stemlike neural precursors from human glioblastoma. Cancer Res. 2004;64(19):7011-21. doi: 10.1158/0008-5472.can-041364.

16. Jin $F$, Zhao L, Zhao HY, Guo SG, Feng J, Jiang XB, et al. Paradoxical expression of anti-apoptotic and MRP genes on cancer stem-like cell isolated from TJ905 glioblastoma multiforme cell line. Cancer Invest. 2008;26(4):338-43. doi: 10.1080/07357900701788064.

17. Passegué $\mathrm{E}$, Jamieson CH, Ailles LE, Weissman IL. Normal and leukemic hematopoiesis: are leukemias a stem cell disorder or a reacquisition of stem cell characteristics? Proc Natl Acad Sci U S A. 2003;100 Suppl 1(Suppl 1):11842-9. doi: 10.1073/ pnas.2034201100. 